\title{
Glycine powder therapy on a hairy tongue: A case report.
}

\author{
Casu $\mathrm{C}^{1^{*}}$ and Vigano $\mathrm{L}^{2}$ \\ ${ }^{1}$ DDS Private Dental Practice, Cagliari, Italy. \\ ${ }^{2}$ Department of Radiology, University of Milan, Milano, Italy
}

\begin{abstract}
Black hairy tongue (BHT) is a benign condition characterized by a discolored, hairy appearance of the dorsal tongue. The lesion is distributed on the dorsal aspect of the tongue and does not involve the lateral and the tip site of the tongue. The most common discoloration of the tongue in this condition is black to blackish-brown, but it can present with green or yellow discoloration or can lack pigmentation altogether. Glycin powder is described in the literature for the treatment of periodontitis and per implantitis, but never is it used for treatment of hairy tongue. 50-year-old male patient came to our observation showed a whitish film on the tongue with hypertrophy of the filiform papillae, typical of a hairy tongue. It is decided to treat the patient with glycine powder using an airflow hand piece. The powder was insufflated for about 2 minutes on the lingual central surface. 7 days after the lingual lesion healed. The use of glycin powder is considered safe and effective in the literature, especially in removing biofilms. This case report could be the starting point for randomized clinical trials that investigate the use of glycine powder in treatment of hairy tongue.
\end{abstract}

Keywords: Discoloration, Papillae, Tongue, Glycin powder.

Accepted on March 02, 2018

\section{Introduction}

Black hairy tongue (BHT) is a benign condition characterized by a discolored, hairy appearance of the dorsal tongue. The prevalence of BHT is not known because its occurrence is highly variable among different populations and dependent on many factors; BHT is more common in men, elderly patients, smokers, HIV-positive patients, edentulous patients, and patients with cancer [1]. The lesion is distributed on the dorsal aspect of the tongue and does not involve the lateral and the tip site of the tongue. The most common discoloration of the tongue in this condition is black to blackish-brown, but it can present with green or yellow discoloration or can lack pigmentational together. This disease is often asymptomatic, but sometimes is associated with alitosis, limphoadenopathy, burning or tickling sensation [1,2]. Besides poor oral hygiene, many substances and medications could cause, aggravate, or predispose a patient to BHT, for example, smoking tobacco, excess consumption of beverages such as black tea, coffee, alcohol, oxidizing mouthwashes, and also intravenous drug use are linked to an increased prevalence of BHT [1,2]. This condition is benign, self-limiting, and the diagnosis is based on clinical presentation. First-line treatments include avoiding associated medications, practicing good oral hygiene, discontinuing habits predisposing to BHT, and gentle brushing or scraping of the tongue [1]. Glycin powder is described in the literature for the treatment of periodontitis and perimplantitis $[3,4]$, but never it is used for treatment of hairy tongue. We would document a particular case of hairy tongue successfully treated with glycin powder.

\section{Case Report}

A 50-year-old male patient came to our observation to treat some dental elements and for a slight burning of the tongue. The anamnesis reported psychiatric problems (schizophrenia), and he told us to use benzodiazepine and other sedative drugs. There was a condition of poor oral hygiene and difficulty in lingual motility. The tongue showed a whitish film with hypertrophy of the filiformpapillae, typical of a hairy tongue (Figure 1). Given the little cooperation of the patient to perform topical therapies and to maintain good oral hygiene, it is decided to treat the patient with glycine powder using an airflow hand piece (PerioMate, Nsk, Japan). The powder was insufflated for about 2 minutes on the lingual central surface (Figure 2). The powder was then removed by rinsing with water for 30 seconds. At the next follow-up visit, at 7 days, the patient showed a remission of the hairy tongue in the areas treated with glycine powder (Figure 3).

\section{Discussion}

First-line treatments for BHT include avoiding associated medications, practicing good oral hygiene, and gentle brushing

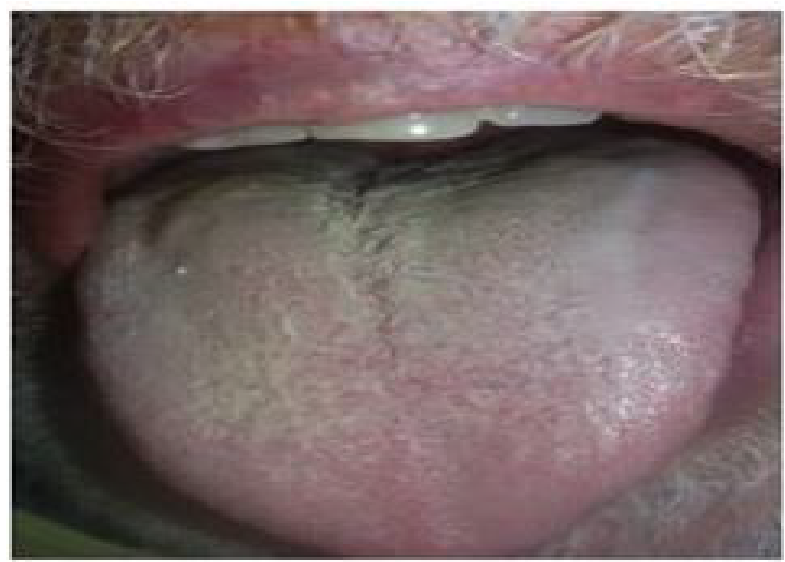

Figure 1. Tongue showed a whitish film with hypertrophy of the filiformpapillae. 


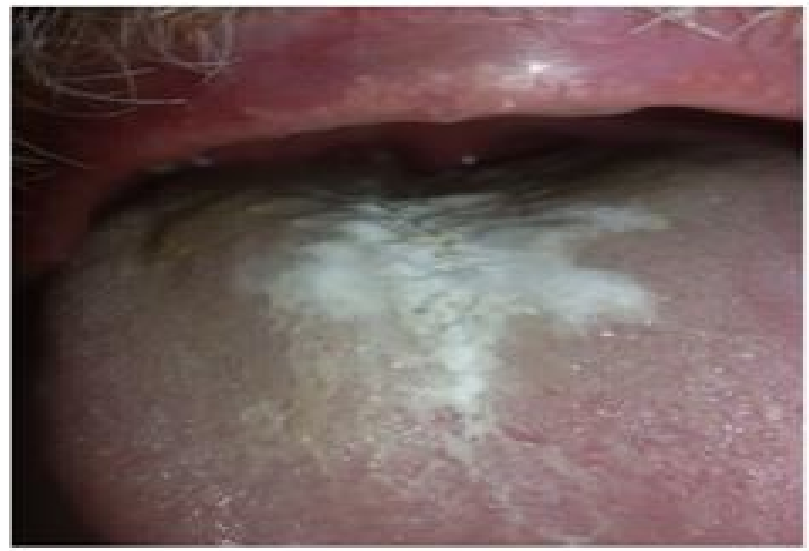

Figure 2. Lingual central surface of the tongue.

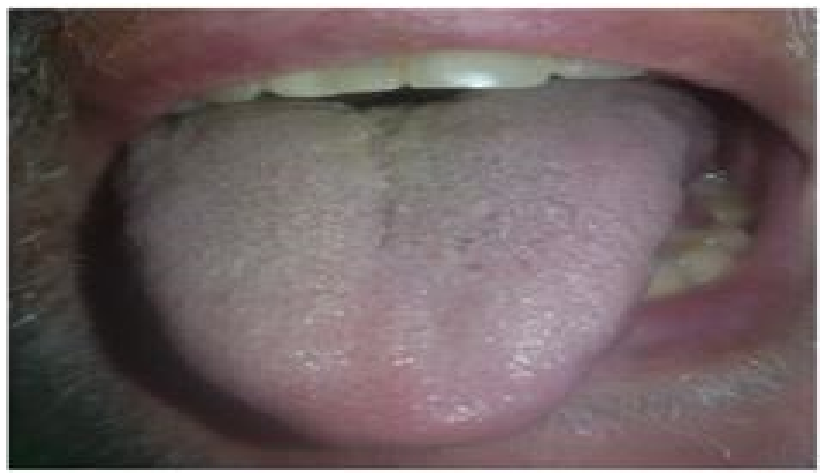

Figure 3. Hairy tongue in the areas treated with glycine powder.

or scraping of the tongue [1], but are not simple in a patient with poor compliance. The consensus conference of 2017 reported that supra and sub gingival air polishing using glycine powder is safe and effective for removal of biofilms from natural tooth structure and restorative materials; the authors also concluded that there is no evidence of soft-tissue abrasion when using glycine powder in an air-polishing device [3]. The use of glycine powder treatment in a study had determined clinically significant improvement in plaque and gingival index scores. Histologically causes less gingival erosion than sodium bicarbonate or ultrasonic instrumentation [5]. Grundstrom et al. found that treatment with a glycine powder air-polishing device is effective in non-surgical treatment of periimplant mucositis [6]. Lupi et al. concluded that treatment with glycine seems appropriate in the maintenance of peri-implant health and more effective than the traditional treatment with plastic curette and chlorhexidine [4]. Glycine powder is proposed also in the conservative therapy [7].

\section{Conclusion}

A recent review, considered 1266 articles screened, and included 17 studies analysis. The data found, confirmed the safety and the effectiveness of this type of treatment, especially in removing biofilms [8]. This case report could be the starting point for randomized clinical trials that investigate the use of glycine powder in treatment of hairy tongue.

\section{References}

1. Gurvits GE, Tan A. Black hairy tongue syndrome. World J Gastroenterol. 2014;20:10845-50.

2. Schlager E, Chelsea St. Claire P, et al. Black hairy tongue: Predisposing factors, diagnosis and treatment. Am J Clin Dermatol. 2017; 18:563-9.

3. Cobb CM, Daubert DM, Davis K, et al. Consensus Conference Findings on supragingival and subgingival air polishing. Compend Contin Educ Dent. 2017;38:e1-e4.

4. Lupi SM, Granati M, Butera A, et al. Air-abrasive debridement with glycine powder versus manual debridement and chlorhexidine administration for the maintenance of peri-implant health status: a sixmonthrandomized clinical trial. Int $\mathrm{J}$ Dent Hyg. 2017;15:287-294.

5. Simon CJ, Venkatesh MLVP, Chickanna R. Efficacy of glycine powder air polishing in comparison with sodium bicarbonate air polishing and ultrasonic scaling - a doubleblind clinico-histopathologic study. Int $\mathrm{J}$ Dent Hyg. 2015;13:177-83.

6. Riben-Grundstrom C, Norderyd O, André U, et al. Treatment of peri-implant mucositis using a glycine powder air-polishing or ultrasonic device: a randomized clinical trial. J Clin Periodontol. 2015;42:462-9.

7. Barnes CM, Covey D, Watanabe H, et al. An in vitro comparison of the effects of various air polishing powders on enamel and selected esthetic restorative materials. J Clin Dent. 2014;25:76-87.

8. Buhler J, Amato M, Weiger R, et al. A systematic review on the effects of air polishing devices on oral tissues. Int J Dent Hyg. 2016;14:15-28.

\section{*Correspondence to:}

Casu C

DDS Private Dental Practice, Cagliari,

Italy,

Tel: +393408422435

E-mail: ginzia.85@hotmail.it 